\title{
Nutrient inputs and net ecosystem productivity in the mouth of the Magdalena River, Colombia
}

Ana Carolina Torregroza-Espinosa; Juan Camilo Restrepo; Jaime Escobar; Mark Brenner; Alice Newton.

\section{Abstract}

Nutrient inputs and biogeochemical cycles in estuaries are strongly influenced by river discharge and suspended particulate matter (SPM). We evaluated temporal differences in nutrient bioavailability and net ecosystem productivity (NEP) and analyzed the effect of SPM on nutrient availability and estuary NEP in the mouth of the Magdalena River, Colombia. In this study, we used the stratified Muddy LOICZ model. Calculated water residence times in the estuary were low ( 0.9-2.1 days), as were proportions of dissolved nitrogen (DIN) and phosphorus (DIP) forms $(\sim 10-30 \%)$ in the total nutrient pool. Dissolved nutrient proportions displayed differences between seasons (transition period [June 2018] and wet [November 2018]), and between the upper and lower, density-stratified water layers. Nutrient adsorption and desorption, associated with SPM in the estuary, determined bioavailable nutrient concentrations. When SPM was incorporated in the Muddy LOICZ model, the output indicated that NEP in the estuary was positive, i.e. gross primary productivity exceeded community respiration (autotrophic), and that there was net retention of nitrogen and phosphorus in the estuary. Primary producers in the autotrophic ecosystem fix sufficient carbon to supply higher trophic levels. Prevalence of fine sediment with high organic matter (OM) content in the Magdalena River, along with turbulence that results in vertical water column mixing, suggest conditions conducive to flocculation. This investigation highlights the importance of the Magdalena River mouth in the transport and processing of sediments and nutrients being discharged to the Caribbean Sea.

Keywords: Nutrients, Suspended particulate matter (SPM), Stratified estuary, Partition (distribution) coefficient, Net ecosystem productivity (NEP), Muddy LOICZ model 